\title{
Avaliação da Degradabilidade Ruminal in situ da Palha de Arroz Fermentada por Trichoderma viride, Rhizopus stolonifer e Pycnoporus sanguineus ${ }^{1}$
}

\author{
Eliane Endres ${ }^{2}$, Robert W. S. P. Thomas ${ }^{3}$, Ênio Rosa Prates ${ }^{4}$
}

\begin{abstract}
RESUMO - O melhoramento nutricional da palha de arroz fermentada por Trichoderma viride, Rhizopus stolonifer e Pycnoporus sanguineus foi avaliado por intermédio da degradação ruminal in situ. A fermentação da palha com $T$. viride e água por duas semanas aumentou a taxa de degradação ruminal em, aproximadamente, 31,5 e 264\%, respectivamente, quando comparada com controle e água e com fermentação da palha por uma semana. Houve, também, redução no tempo de degradação efetiva da matéria seca da palha de arroz no trato digestivo do animal. O tratamento com $R$. stolonifer é água mostrou aumento de 17,95 e 7,90\% da fração potencialmente digestível da matéria seca da palha, respectivamente, quando comparada com controle e fermentação por uma semana. O tratamento da palha de arrroz com P. sanguineus e água mostrou redução de 6,66 e 33,64\% na degradação ruminal efetiva da matéria seca da palha após fermentação por uma e duas semanas, respectivamente.
\end{abstract}

Palavras-chave: degradabilidade ruminal, palha de arroz, Pycnoporus sanguineus, Rhizopus stolonifer, Trichoderma viride

\section{Evaluation of Rice Straw Fermented by Trichoderma viride, Rhizopus stolonifer and Pycnoporus sanguineus by in situ Ruminal Degradability}

\begin{abstract}
The nutritional improvement of rice straw fermented by Trichoderma viride, Rhizopus stolonifer and Pycnoporus sanguineus was evaluated using the in situ ruminal degradability technique. The fermentation of the straw with $T$. viride and water for two weeks increased the degradation rate in 31.5 and $264 \%$ when compared with the control and water, and with fermentation of the straw for one week. Also, there was a reduction on the effective degradation time of the straw dry matter in the digestive tract of the animal. The treatment with $R$. stolonifer and water showed an increase of 17.95 and $7.90 \%$ on the potentially digestible fraction of the straw dry matter, respectively, when compared with the control and fermentation by one week. The treatment of straw with $P$. sanguineus and water showed reduction of 6.66 and $33.64 \%$ on the effective ruminal degradability of the straw dry matter after one and two weeks of fermentation, respectively.
\end{abstract}

Key Words: rumen degradability, rice straw, Pycnoporus sanguineus, Rhizopus stolonifer, Trichoderma viride

\section{Introdução}

A indústria agrícola no Estado do Rio Grande do Sul produz, anualmente, cerca de $2500000 \mathrm{t}$ de palha de arroz, sendo a maioria descartada.

As palhas são constituídas de fibras ricas em celulose (30 a 45\%), hemicelulose (16 a 36\%), lignina (7 a 10\%), sílica (3 a 13\%) e cinzas, com $10 \%$ de umidade (JAYASURIYA, 1983). A lignina, na parede celular da planta, não apenas se incrusta nas microfibrilas de celulose e hemicelulose, mas também está quimicamente ligada a estes carboidratos, o que fisicamente limita muito o ataque microbiano (CHAHAL e MOO-YOUNG, 1981). Segundo VAN SOEST e WINE (1968), o teor de lignina é o que, em geral, limita a digestibilidade das palhas pelos ruminantes e, no caso da palha de arroz, não é muito alto
- cerca de 4,4\% -, mas em sílica $\left(\mathrm{SiO}_{2}\right)$ a palha de arroz se destaca sobre as outras em sua riqueza, sendo a menos digestível. Esses dados são confirmados também por FREITAS (1992).

O tratamento deste material é essencial antes de ser utilizado como alimento animal, pois, sem tratamento ou suplementação, as palhas não são adequadas nem mesmo para rações de manutenção (PRATES e LEBOUTE, 1980). Os tratamentos podem ser físicos ou químicos. Os físicos incluem a redução do tamanho das partículas, aplicação de calor úmido e radiações gama e/ou ultravioleta. Em geral, estes métodos são anti-econômicos quando aplicados em grande escala. Os tratamentos químicos incluem $\mathrm{NaOH}$ e agentes oxidantes, como $\mathrm{SO}_{2}, \mathrm{H}_{2} \mathrm{O}_{2}, \mathrm{O}_{3}$ etc. Entretanto, segundo CHAHAL e MOO-YOUNG (1981), o tratamento com álcalis remove, além de

\footnotetext{
${ }^{1}$ Parte da dissertação de Mestrado do primeiro autor apresentada à UFRGS.

2 M.S.c., Professora da Faculdade de Medicina Veterinária da UNIMES. Santos, SP

3 Ph.D., Professor Visitante do Departamento de Solos da Faculdade de Agronomia da UFRGS

${ }^{4}$ PhD., Professor do Curso de Pós-graduação em Zootecnia da UFRGS. Bolsista do CNPq.
} 
lignina, a hemicelulose, o que significa grande perda, quando o objetivo é a alimentação animal. Além de apresentar problemas práticos, os produtos químicos utilizados no processo são potencialmente perigosos ao usuário, podendo causar também contaminação ambiental (KARUNANANDAA et al., 1995).

Além destes tratamentos, existe a possibilidade de utilização de meios biológicos para a mesma finalidade. Existem microrganismos que têm capacidade de utilizar lignocelulose, os quais poderiam melhorar o valor nutritivo deste material por meio de fermentação em estado sólido (VOLLBRECHT, 1997). Neste processo há formação de biomassa que também pode quebrar as ligações lignina-carboidrato, expondo os polissacarídeos ao ataque microbiano no rúmen do animal (JALC et al., 1997). Este tema ainda carece de exploração, pois alguns destes microrganismos utilizam lignina, sem melhorar a degradabilidade ruminal do substrato, e outros que não a utilizam, porém melhoram a degradabilidade ruminal (ENDRES, E. não publicado). Entretanto, AKIN et al. (1993), após testarem uma série de fungos causadores de podridão branca, concluíram que Ceriporiopsis subvermispora causou perda significante de lignina de talos de gramíneas, além de ter provocado melhora do material, devido à utilização da biomassa pelos microrganismos ruminais. KARUNANANDAA et al. (1995) conseguiram aumentar a digestibilidade da matéria seca de palha de arroz utilizando os fungos Cyathus stercoreus e Phanerochaete chrysosporium (causadores de podridão branca), indicando que o tratamento de tecidos lignificados com certos fungos facilita a penetração de microrganismos ruminais em tais tecidos.

Este trabalho teve como objetivo investigar a capacidade de Trichoderma viride, Rhizopus stolonifer e Pycnoporus sanguineus em fermentar lignocelulose e melhorar a degradabilidade ruminal do composto formado pela fermentação em estado sólido de palha de arroz. Estes microrganismos foram isolados da região de Porto Alegre (RS) em ensaios preliminares e são provenientes do solo (R. stolonifer e $T$. viride) e da madeira ( $P$. sanguineus).

\section{Material e Métodos}

A palha de arroz utilizada neste experimento apresentou, em média, 90,5\% de matéria seca (MS), $79,92 \%$ de fibra em detergente neutro (FDN), 55,48\% de fibra em detergente ácido (FDA), 24,44\% de hemicelulose, 49,38\% de celulose e 6,09\% de lignina, conforme análises preliminares. Para cada tratamen- to utilizaram-se $10 \mathrm{~g}$ da palha, que foi moída em moinho tipo Wiley de malha $2 \mathrm{~mm}$, aos quais foram adicionados $30 \mathrm{~mL}$ de água destilada (controles) e/ou caldo de sais (meio BUSHNELL e HAAS (1941), utilizado para fermentação com $T$. viride e $P$. sanguineus e meio KAUFMANN e KEARNEY (1965) para $R$. stolonifer) a $\mathrm{pH} 6$ e autoclavagem feita a $121^{\circ} \mathrm{C}$ por 20 minutos (de acordo com recomendações de ensaios preliminares). A inoculação foi realizada a partir de discos de micélio fúngico, com $1,6 \mathrm{~cm}$ de diâmetro, de cada isolado crescido em ágar batata-dextrose (ABD) a $\mathrm{pH} 6$ (um disco para cada frasco contendo $10 \mathrm{~g}$ de palha). Foram feitas quatro repetições para cada tratamento.

Os tratamentos foram estudados em dois períodos de fermentação, 7 e 14 dias, em estufa a $28^{\circ} \mathrm{C}$, mantendo-se a umidade de $70 \%$ até o final dos períodos (TRIPATHI e YADAV, 1991).

Após a fermentação, os frascos foram colocados em estufa com ar forçado a $60^{\circ} \mathrm{C}$, por três dias, para secagem do material. O material seco, de cada frasco, foi moído em moinho tipo Wiley com $1 \mathrm{~mm}$ de malha.

Para determinação da degradabilidade ruminal, foram utilizadas amostras de $5 \mathrm{~g}$ em sacos de náilon de $20 \times 10 \mathrm{~cm}$ e poros de 40 micras. Além disso, foram necessários três novilhos fistulados no rúmen, que receberam $4 \mathrm{~kg}$ de feno de alfafa, pastagem à vontade e $50 \mathrm{~g}$ de mistura de sal mineralizado diariamente. Foram testados três horários de incubação, 6, 24 e 96 horas, como proposto por SAMPAIO (1991).

A degradabilidade da matéria seca (MS) foi descrita por intermédio dos modelos propostos por ORSKOV e McDONALD (1979), P = a + b (1 - exp ${ }^{-}$ $\left.{ }^{c t}\right)$ e $p=a+b c / c+k$, em que $\mathbf{p}$ é a degradação efetiva; $\mathbf{k}$, a taxa de passagem; $\mathbf{P}$, a degradabilidade potencial; a, a fração solúvel; b, a fração potencialmente degradável; e c, a taxa constante de degradação.

Os resultados da degradabilidade in situ foram analisados conforme delineamento em quadrado latino com parcelas sub-sub-divididas. As parcelas principais representaram os horários de incubação; as subparcelas, o tempo de fermentação (7 e 14 dias); e as sub-sub-parcelas, os fungos. O efeito dos tratamentos foi avaliado por análise de variância e a significância dos contrastes de médias foi determinada pelo teste de Tukey (GOMES, 1985).

\section{Resultados e Discussão}

As amostras tratadas com T. viride e $R$. stolonifer, por 7 ou 14 dias (Tabelas 1 e 2), tiveram 
degradação efetiva da MS semelhante, ao passo que com a utilização de $P$. sanguineus foi menor aos 14 dias de fermentação $(\mathrm{P}<0,01)$. Estes resultados não eram esperados, visto que $P$. sanguineus é um organismo conhecido por sua habilidade ligninolítica (ZADRAZIL, 1985; ROLZ et al., 1987); assim, a degradabilidade ruminal deveria ter sido aumentada quando comparada ao controle, como foi relatado por ROLZ et al. (1986). De acordo com ZADRAZIL (1980), AKIN (1988) e JUNG (1989), a presença de lignina, óxido de sílica e a cristalinidade da celulose são fatores que diminuem a digestibilidade ruminal dos polissacarídeos da parede celular das plantas. Entretanto, outros autores, ROLZ et al. (1987), JUNG et al. (1992) e KARUNANANDAA et al. (1995), não encontraram relação direta entre a degradação de lignina e a melhora na digestibilidade da MS. KARUNANANDAA et al. (1995) sugerem que a inibição da digestibilidade da MS pode ser causada por produtos da degradação parcial de lignina, que seriam tóxicos para os microrganismos ruminais, ou, de certa forma, poderiam inativar as enzimas diges- tivas. O efeito de deligninficação e a melhora da degradabilidade ruminal dependem de vários fatores, sendo o tipo de fungo utilizado o mais importante. Esses autores obtiveram resultados positivos na digestibilidade in situ da palha de arroz tratada com Cyathus stercoreus.

Conforme o resultado obtido com palha fermentada 14 dias por $P$. sanguineus e meio mineral Bushnell-Haas, houve aumento da degradação da MS com 24 e 96 horas de incubação ruminal, quando comparado com o tratamento da palha com água, mesmo período de fermentação e fungo (Tabela 3). Este resultado pode ser explicado pela presença de $\mathrm{N}$ e outros elementos misturados no produto obtido da fermentação, que não foram utilizados pelo fungo. Estes minerais podem ter facilitado a degradação do material pelos microrganismos ruminais, elevando a degradação do controle em cerca de 12 unidades percentuais em 96 horas de incubação.

A utilização de microrganismos celulolítico ( $T$. viride) e hemicelulolítico ( $R$. stolonifer) pode ter provocado redução da fração disponível ao ataque

Tabela 1 - Valores individualizados para as constantes $a, b$ e $c$, degradação potencial (DP), degradação efetiva (DE) e tempo (T) para ocorrer a DE da palha fermentada por uma semana

Table 1 - Individual values for the constants $a, b$ and $c$, for the potential degradation (PD), effective degradation $(E D)$ and time $(T)$ to occur the effective degradation of the rice straw fermented for one week

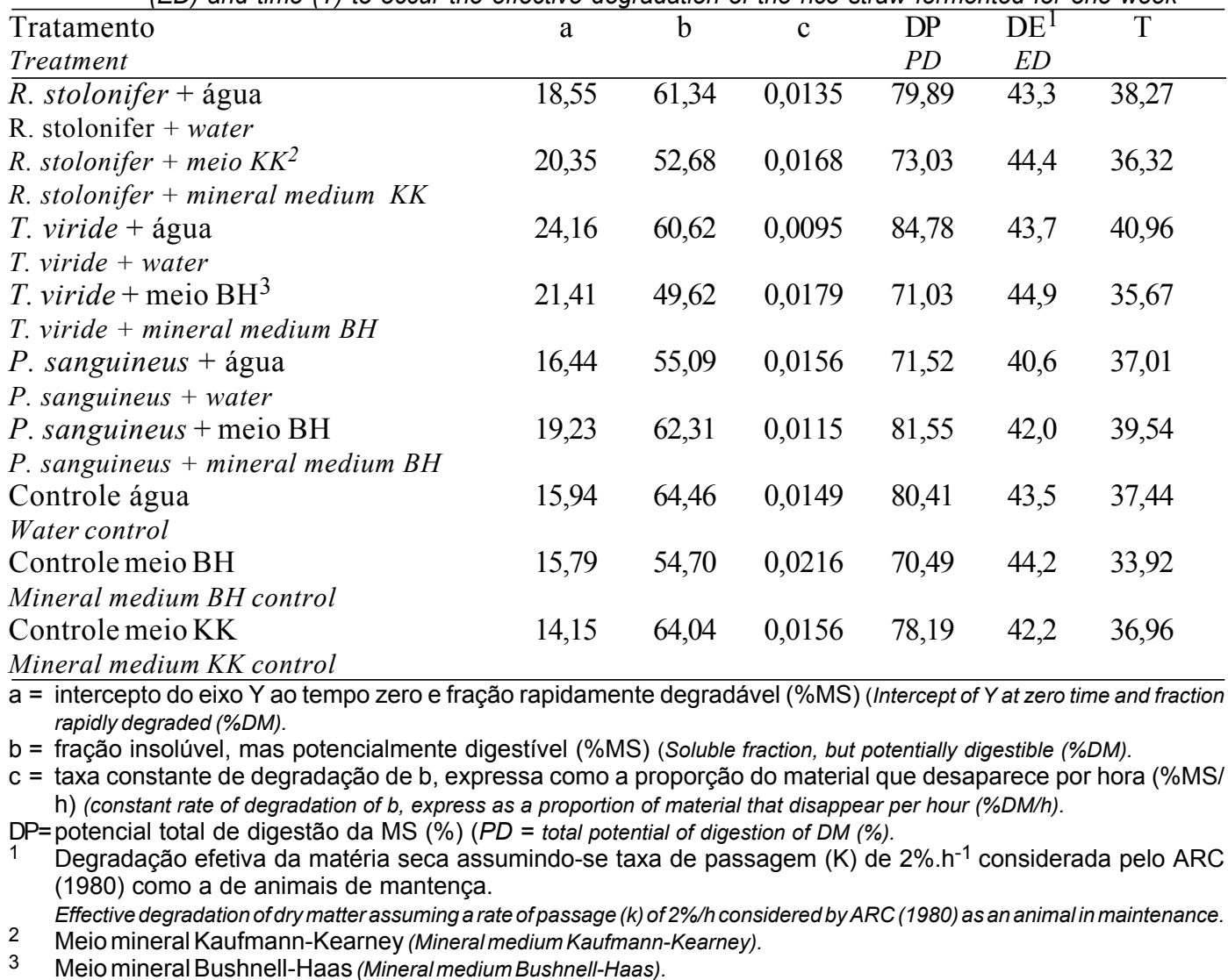


ENDRES et al.

Tabela 2 - Valores individualizados para as constantes $a, b$ e $c$, degradabilidade potencial (DP), degradação efetiva (DE) e tempo $(T)$ para ocorrer a $D E$ da palha fermentada por duas semanas

Table 2 - Individual values for the constants $a, b$ and $c$, for the potential of degradation (PD), effective degradation (ED) and time $(T)$ to occur the effective degradability of the rice straw fermented for two weeks

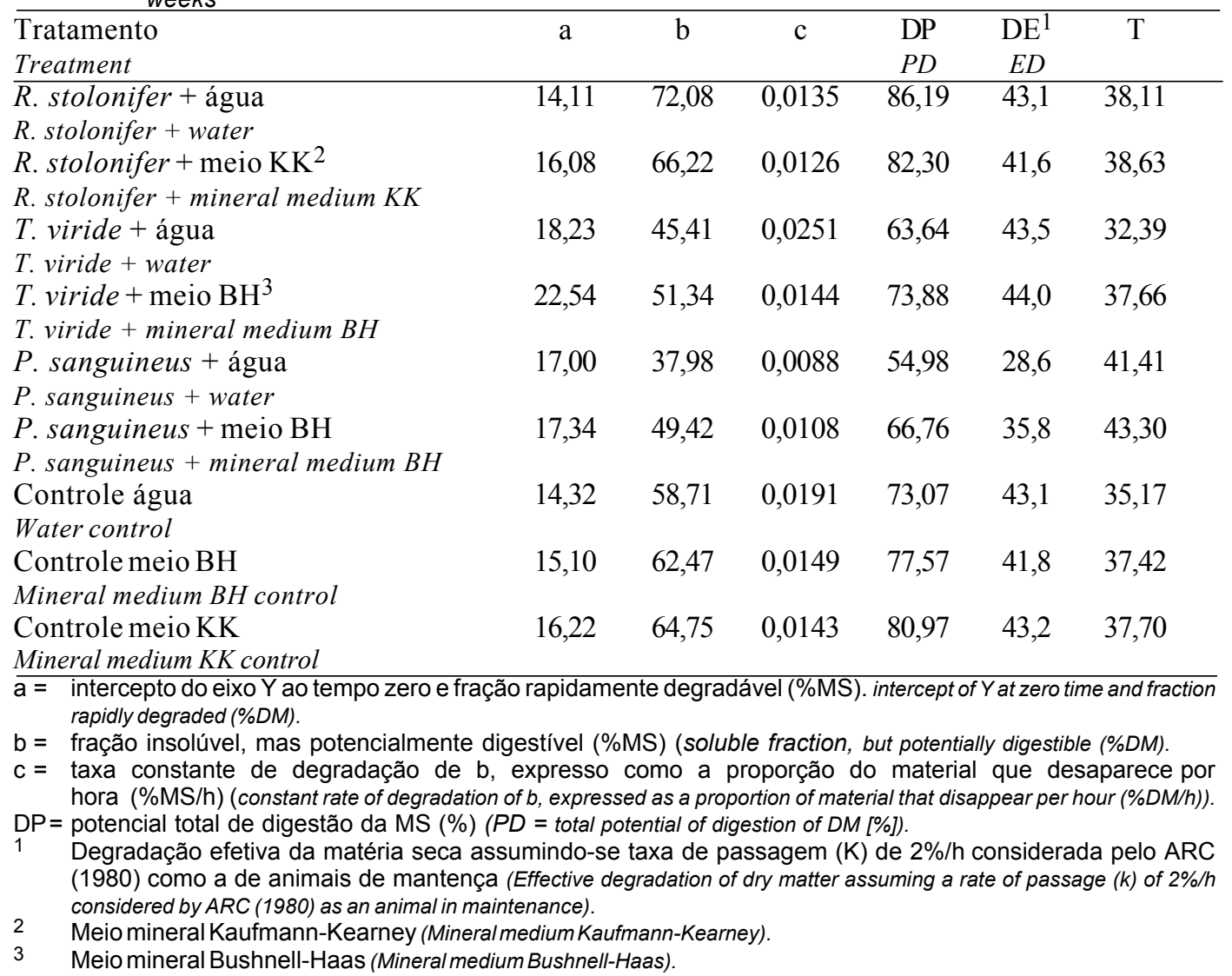

microbiano (carboidratos), porém não causou diminuição ( $\mathrm{P}>0,01)$ da degradabilidade da MS da palha. De acordo com estes resultados, existe possibilidade de que a biomassa fúngica tenha melhorado, em termos compensatórios, a degradabilidade ruminal da MS, fazendo com que os valores se tornassem semelhantes $(\mathrm{P}>0,01)$ aos obtidos na degradação dos controles.

De acordo com os resultados encontrados para o desaparecimento da MS da palha, fermentada 7 dias com $R$. stolonifer, e os controles (água e meio mineral) (Tabela 1), não houve diferença relevante na DE destes; no entanto, a degradabilidade potencial (DP) teve aumento considerável no tratamento de 14 dias de fermentação da palha (Tabela 2). Este resultado pode ter ocorrido devido ao aumento da fração insolúvel b, potencialmente degradável, do composto, possivelmente quitina. Em outras palavras, o aumento desta fração insolúvel e a taxa de degradação tendo permanecido a mesma implicam maior permanência do alimento (material fermentado) no trato digestivo do animal, aumentando o contato com os microrganis- mos do rúmen, o que vem a ser benéfico para a absorção dos nutrientes (ORSKOV e RYLE, 1990).

A fermentação de 14 dias da palha com $T$. viride e água mostrou aumento da taxa de degradação, c, isto é, maior quantidade de material foi degradada por hora de fermentação ruminal in situ. Entretanto, houve redução de cerca de $24,0 \%$ da fração insolúvel b, da fração solúvel a, e do potencial total de digestão da MS, possivelmente devido à utilização da hemicelulose e celulose pelo fungo. $\mathrm{O}$ material fermentado nessas condições apresentou melhora em termos de valor nutritivo, pois a DE de $43,5 \%$ da $\mathrm{MS}$ ocorreu em 32h23, contra 40h58 (Tabelas 1 e 2), resultado semelhante ao encontrado por UNDI e WITTENBERG (1996), que relacionam maior biomassa fúngica com maior $\mathrm{DE}$. Como conseqüência deste resultado, espera-se aumento no consumo de alimento, devido à mais rápida degradação ruminal do material.

A fermentação da palha com $T$. viride e meio mineral $\mathrm{BH}$ aparentemente não causou alterações nas características da degradabilidade do material, 
Tabela 3 - Efeitos da interação tríplice entre fungos, tempo de fermentação e período de incubação ruminal sobre a degradabilidade da matéria seca (\%) da palha de arroz

Table 3 - Effects of a triplice interaction between fungi, fermentation time and period of ruminal incubation on dry matter degradability (\%) of the rice straw

\begin{tabular}{|c|c|c|c|c|}
\hline & & \multicolumn{3}{|c|}{$\begin{array}{l}\text { Período de incubação } \\
\text { Incubation period }\end{array}$} \\
\hline \multirow{2}{*}{$\begin{array}{l}\text { Tempo de fermentação } \\
\text { Fermentation time }\end{array}$} & Tratamento & $6 \mathrm{~h}$ & $24 \mathrm{~h}$ & $96 \mathrm{~h}$ \\
\hline & Treatment & & & \\
\hline \multirow{18}{*}{ 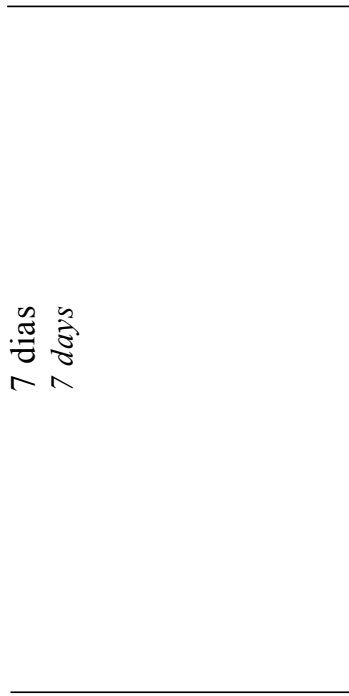 } & R. stolonifer + água & $23,33^{\mathrm{a}}$ & $35,56^{\mathrm{a}}$ & $63,16^{\mathrm{a}}$ \\
\hline & R. stolonifer + water & & & \\
\hline & R. stolonifer + meio $\mathrm{KK}^{1}$ & $26,77^{\mathrm{a}}$ & $35,77^{\mathrm{a}}$ & $63,21^{\mathrm{a}}$ \\
\hline & R. stolonifer + mineral medium $K K^{l}$ & & & \\
\hline & T. viride + água & $27,52^{\mathrm{a}}$ & $36,52^{\mathrm{a}}$ & $60,43^{\mathrm{a}}$ \\
\hline & T. viride + water & & & \\
\hline & T. viride + meio $\mathrm{BH}^{2}$ & $27,86^{\mathrm{a}}$ & $36,70^{\mathrm{a}}$ & $62,93^{\mathrm{a}}$ \\
\hline & T. viride + mineral medium $B H^{2}$ & & & \\
\hline & $P$. sanguineus + água & $21,36^{\mathrm{a}}$ & $33,64^{\mathrm{a}}$ & $59,20^{\mathrm{a}}$ \\
\hline & P. sanguineus + water & & & \\
\hline & P. sanguineus + meio $\mathrm{BH}$ & $23,38^{\mathrm{a}}$ & $34,24^{\mathrm{a}}$ & $60,85^{\mathrm{a}}$ \\
\hline & $P$. sanguineus + mineral medium $B H$ & & & \\
\hline & Controle água & $21,47^{\mathrm{a}}$ & $35,37^{\mathrm{a}}$ & $65,05^{\mathrm{a}}$ \\
\hline & Water control & & & \\
\hline & Controle meio BH & $22,43^{\mathrm{a}}$ & $37,89^{\mathrm{a}}$ & $63,59 \mathrm{a}$ \\
\hline & Mineral medium $B H$ & & & \\
\hline & Controle meio KK & $21,67 \mathrm{a}$ & $31,47 \mathrm{a}$ & $64,72_{\mathrm{a}}$ \\
\hline & Mineral medium $K K$ & & & \\
\hline \multirow{17}{*}{ 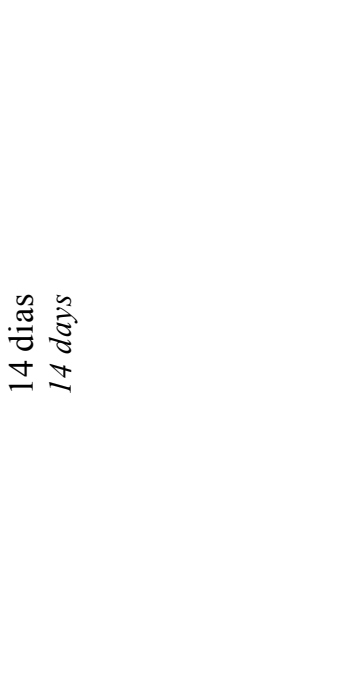 } & R. stolonifer + água & $19,70_{\mathrm{a}}$ & $34,00_{a}$ & $66,38_{a}$ \\
\hline & R. stolonifer + water & & & \\
\hline & R. stolonifer + meio KK & $20,88_{\mathrm{a}}$ & $33,30_{a}$ & $62,44_{a}$ \\
\hline & R. stolonifer + mineral medium $K K$ & & & \\
\hline & T. viride + água & $24,57 \mathrm{a}$ & $38,75_{\mathrm{a}}$ & $59,55_{a}$ \\
\hline & T. viride + water & & & \\
\hline & T. viride + meio $\mathrm{BH}$ & $28,20_{\mathrm{a}}$ & $35,47 \mathrm{a}$ & $61,63 \mathrm{a}$ \\
\hline & T. viride + mineral medium $B H$ & & & \\
\hline & $P$. sanguineus + água & $18,96_{\mathrm{a}}$ & $24,25_{b}$ & $38,70_{b}$ \\
\hline & P. sanguineus + water & & & \\
\hline & P. sanguineus + meio $\mathrm{BH}$ & $21,76_{\mathrm{a}}$ & $26,77_{b}$ & $49,75_{b}$ \\
\hline & P. sanguineus + mineral medium $B H$ & & & \\
\hline & Controle água & $22,34_{a}$ & $33,46_{a}$ & $64,63_{\mathrm{a}}$ \\
\hline & Controle meio $\mathrm{BH}$ & 2044 & 3587 & 6261 \\
\hline & Mineral medium $\mathrm{BH}$ & & $J J, 01 \mathrm{a}$ & $0 \angle, 01 \mathrm{a}$ \\
\hline & Controle meio KK & $21,54_{a}$ & $35,02_{\mathrm{a}}$ & $64,55_{a}$ \\
\hline & Mineral medium $K K$ & & & \\
\hline
\end{tabular}

Médias, na coluna, seguidas por letras diferentes são diferentes pelo teste Tukey $(P<0,01)$.

Means, within a column, followed by different letters are different by Tukey test $(P<.01)$.

1 Meio mineral Kaufmann-Kearney (Mineral medium Kaufmann and Kearney).

2 Meio mineral Bushnell-Haas Mineral (Medium Bushnell and Haas).

pois os valores encontrados nos dois períodos de fermentação foram semelhantes (Tabelas 1 e 2).

O tratamento da palha com $P$. sanguineus provocou alterações nas características da degradabilidade do material, mostrando redução na DE, após duas semanas de fermentação, de aproximadamente $30 \mathrm{e}$ $15 \%$, com água e com meio $\mathrm{BH}$, respectivamente. Além deste resultado, constatou-se que aumentou o tempo para ocorrer a $\mathrm{DE}$, havendo necessidade de mais de 40 horas de fermentação ruminal para serem degradados apenas de 28,6 a $35,8 \%$ da MS da palha (Tabela 2). A fração solúvel quase não sofreu altera- ção, tanto na fermentação com água como com meio $\mathrm{BH}$, porém, com a utilização de água e duas semanas de fermentação, houve sensível diferença na fração insolúvel, que reduziu em torno de $31 \%$, ficando bem abaixo da média (Tabela 2). Isto indica que, além do fungo ter utilizado celulose e hemicelulose, possivelmente houve formação de algum composto que dificultou a degradação, pois a taxa constante de degradação também diminuiu de 1,56 para $0,88 \% \mathrm{MS} / \mathrm{h}$, ou seja, menor quantidade de material passou a ser degradado por hora de incubação. Outra possibilidade seria que a quebra de algumas ligações da lignina 
teria provocado liberação de compostos fenólicos tóxicos, inibindo o ataque microbiano do material contido nos sacos de incubação (JUNG, 1989). No trabalho realizado por KARUNANANDAA et al. (1995), o tratamento de palha de arroz com Cyathus stercoreus - também causador de podridão branca , por 30 dias de fermentação, resultou em maior desaparecimento da MS pela atividade microbiana do rúmen do que a palha não-tratada. De acordo com os autores, é possível que seja necessário maior tempo de fermentação com o fungo, devido à presença de altas concentrações de sílica na palha de arroz.

\section{Conclusões}

De modo geral, todos os tratamentos com fungos melhoraram a degradabilidade ruminal da palha pelo aumento da fração solúvel da matéria seca. A maior taxa de degradação da fração potencialmente digestível foi expressa pela palha de arroz fermentada 14 dias por Trichoderma viride e água.

Pela complexidade deste tema, percebe-se que há dificuldade em formular uma conclusão a respeito da melhora da forragem estudada neste trabalho, devido à ausência de resultados complementares, como por exemplo, análise do desempenho visando à economicidade e praticidade do processamento da palha e a viabilidade do aumento da digestibilidade na redução da matéria seca disponível.

\section{Agradecimentos}

Ao CNPq, pelo apoio financeiro recebido para o desenvolvimento deste trabalho.

\section{Referências Bibliográficas}

AKIN, D.E. 1988. Biological structure of lignocellulose and its degradation in the rumen. Anim. Feed Sci. and Tech., 21:295-310.

AKIN, D.E., SETHURAMAN, A., MORRISON, W.H. et al. 1993. Microbial delignification with white rot fungi improves forage digestibility. Appl. and Environ. Microb., 59(12): 4274-4282.

BUSHNELL, C.D., HAAS, H.I. 1941. The utilization of certain hydrocarbons by microorganisms. J. Bacteriol., 41:654-673.

CHAHAL, D.S., MOO-YOUNG, M. 1981. Bioconversion of lignocellulosics into animal feed with Chaetomium cellulolyticum. Develop. Ind. Microb., 22: 143-159.

FREITAS, E.A.G. Utilização da palha de arroz na alimentação de bovinos e ovinos. Lav. Arrozeira, 45(400):3-7, 1992.

GOMES, F.P. 1985. Curso de estatística experimental. 11 ed. Piracicaba: Nobel. 466p.

JALC, D., SIROKA, P., CERESNAKOVA, Z. 1997. Effect of six species of white-rot basidiomycetes on the chemical composition and rumen degradability of wheat straw. J. Gen. Appl. Microb., 43(3): 133-137.

JAYASURIYA, M.C.N. 1983. The use of fibrous residues in South Asia. In: SHACKLADY, C.A. (Ed.) The use of organic residues in rural communities. Tokyo: The United Nations University. p.40-51.

JUNG, H.G. 1989. Forage lignins and their effects on fiber digestibility. Agron. J., 81:33-38.

JUNG, H.J.G., VALDEZ, F.R., HATFIELD, R.D. et al. 1992. Cell wall composition and degradability of forage stems following chemical and biological delignification. J. Sci. Food and Agric., 58:347-355.

KARUNANANDAA, K., VARGA, G.A., AKIN, D.E. et al. 1995. Botanical fractions of rice straw colonized by whiterot fungi: changes in chemical composition and structure. Anim. Feed Sci. and Tech., 55:179-199.

KAUFMANN, D.D., KEARNEY, P.C. 1965. Microbial degradation of isopropyl N-3-chlorophenylcarbonate and 2chloroethil N-3-chlorophenilcarbonate. Appl. Microb., 13: 443-446.

ORSKOV, E.R., McDONALD, I. 1979. The estimation of protein degradability in the rumen from incubation measurements weighted according to rate of passage. J. Agric. Sci., 92: 499-503.

ORSKOV, E.R., RYLE, M. 1990. Energy nutrition in ruminants. Cambridge: Elsevier Science Publishers. 149p.

PRATES, E.R., LEBOUTE, E.M. 1980. Avaliação do valor nutritivo de resíduos de cultivos e de indústria. R. Soc. Bras. Zootec., 9(2): 248-259.

ROLZ, C., LEON, R. DE, ARRIOLA, M.C. DE et al. 1986. Biodelignification of lemon grass and citronella bagasse by white-rot fungi. Appl. Environ. Microb., 52: 607-611.

ROLZ, C., LEON, R. DE, ARRIOLA, M.C. DE et al. 1987. White-rot fungal growth on sugarcane lignocellulosic residue. Appl. Microb. and Biotech., 25:535-541.

SAMPAIO, I.B.M. Controle do erro experimental em ensaios com ruminantes fistulados. In: REUNIÃO ANUAL DA SOCIEDADE BRASILEIRA DE ZOOTECNIA, 28, 1991, João Pessoa. Anais ... Viçosa: SBZ, p. 198, 1991.

TRIPATHI, J.P., YADAV, J.S. 1991. Comparative ligninolytic and polysaccharolytic potentials of an alkaliphilic Basidiomycete on native ligninocellulose. Intern. Biodeter., 27: 49-59.

UNDI, M., WITTENBERG, K.M. 1996. Intake, rumen fermentation characteristics, and feedstuff in situ digestion kinetics as influenced by fungal biomass in alfafa hay fed to cattle. Anim. Feed Sci. Tech., 61:291-303.

VAN SOEST, P.J., WINE, R.H. 1968.Determination of lignin and cellulose in acid-detergent fiber with permanganate. Journal A.O.A.C., 51(4): 780-785.

VOLLBRECHT, D. 1997. History of solid state fermentation. Chem. Ingen. Technik, 69:1403-1408.

ZADRAZIL, F. 1980. Conversion of different plant waste into feed by basidiomycetes. Eur. J. Appl. Microb. and Biotech., 9: 243-248.

ZADRAZIL, F. 1985. Screening of fungi for lignin decomposition and conversion of straw into feed. Angew. Botanik, 59:433-452.

Recebido em: 02/10/98

Aceito em: 20/03/99 